\title{
Upregulation of NETO2 expression correlates with tumor progression and poor prognosis in colorectal carcinoma
}

\author{
Liang Hu${ }^{1 *+}$, Hai-Yang Chen ${ }^{2 \dagger}$, Jian $\mathrm{Cai}^{3 \dagger}$, Guang-Zhen Yang ${ }^{4 \dagger}$, Dan Feng ${ }^{5}$, Yan-Xia Zhai ${ }^{1}$, Hui Gong ${ }^{1}$, Chen-Ye Qi ${ }^{1}$,
} Yu Zhang ${ }^{1}$, Hao Fu', Qing-Ping Cai ${ }^{6 *}$ and Chun-Fang Gao ${ }^{1 *}$

\begin{abstract}
Background: Neuropilin and tolloid-like 2 (NETO2) has been found to be overexpressed in different human cancers, but its expression pattern and clinical relevance in colorectal carcinoma (CRC) remains unknown.

Methods: Real-time quantitative PCR, western blot and immunohistochemistry analyses were used to analyze the expression of NETO2 in CRC clinical samples. The correlation of NETO2 expression with clinicopathologic features was estimated in a cohort containing 292 patients with primary CRC. Kaplan-Meier and Cox proportional hazards regression analyses were used to assess the prognostic value of NETO2 expression in CRC.

Results: The expression of NETO2 was frequently upregulated in CRC clinical samples at both the mRNA and protein levels, and its upregulation was significantly correlated with poor tumor differentiation ( $p=0.013)$, advanced local invasion $(p=0.049)$, increased lymph node metastasis $(p=0.009)$, advanced TNM stage $(p=0.041)$ and increased patient death $(p=0.001)$. Kaplan-Meier analysis of the complete study cohort revealed that patients with high-NETO2 tumors had a significantly shorter disease-specific survival (DSS) than those with low-NETO2 tumors $(p<0.001)$. Importantly, high levels of NETO2 protein predicted poor DSS for patients with early stage tumors $(p=0.027)$ and for those with advanced stage tumors $(p=0.020)$. Furthermore, multivariate analyses indicated that increased NETO2 expression was an independent unfavorable prognostic factor for patients with early stage tumors (hazard ratio $[\mathrm{HR}]=1.937,95 \% \mathrm{Cl}=1.107-3.390, p=0.021$ ) as well as patients with advanced stage tumors $(\mathrm{HR}=2.241,95 \% \mathrm{Cl}=1.245-4.035, p=0.007)$.
\end{abstract}

Conclusions: Our findings suggest that NETO2 upregulation could serve as a potential biomarker for the prediction of advanced tumor progression and unfavorable prognosis in patients with CRC.

Keywords: NETO2, Colorectal carcinoma, Survival, Prognosis, Biomarker

\section{Background}

Colorectal carcinoma (CRC) is the third most commonly diagnosed cancer in males and the second in females, with an estimated 1.4 million cases and 693,900 deaths occurring in 2012 [1]. Due to changes in dietary patterns and risk factors of lifestyle, the incidence of CRC has continued to increase in historically low-risk regions

\footnotetext{
* Correspondence: lianghudoc@163.com; caiqingpingwcwk@163.com; chunfgao@163.com

${ }^{\dagger}$ Equal contributors

${ }^{1}$ Anal-Colorectal Surgery Institute, 150th Hospital of PLA, Luoyang, China ${ }^{6}$ Department of Gastrointestine Surgery, Changzheng Hospital, Second Military Medical University, Shanghai, China

Full list of author information is available at the end of the article
}

including several countries in Eastern Europe and China during the past decades [2-4]. The prognosis of CRC patients has shown only limited improvement despite advances in treatment approaches over the past few years, and the 5-year relative survival has remained less than $50 \%$ in low-income countries [5, 6]. Currently, stage at diagnosis is still the most important prognostic indicator, and classification according to TNM stage provides valuable prognostic information and guides therapy decisions for CRC patients. However, clinical outcome of CRC patients after surgical resection varies greatly, even when patients are assigned to the same TNM category $[7,8]$. Consequently, there is an urgent 
need to identify novel biomarkers to improve prognosis prediction for patients with CRC.

Neuropilin and tolloid-like 2 (NETO2), a single-pass transmembrane protein and, along with its only paralog NETO1, belongs to the unique subfamily of CUB domainand LDLa-containing proteins [9]. Up to now, most studies have implicated the NETO2 gene in neuron-specific processes. It has been identified that NETO2 and NETO1 proteins function as auxiliary subunits of neuronal kainate receptors (KARs), which play important roles in excitatory synaptic transmission in the vertebrate brain [10], and modulate the kinetics of KARs by slowing desensitization or accelerating recovery from desensitization for these receptors $[11,12]$. Therefore, it is proposed that NETO2, as well as NETO1, may provide an alternative target for the development of new drugs regulating KARs and brain function [13]. Mechanistic investigations have revealed that NETO2 could interact with the scaffolding protein Glutamate receptor-interacting protein (GRIP) and regulate synaptic abundance of KARs [14]. In addition, NETO2 has been demonstrated to be a $\mathrm{K}^{+}-\mathrm{Cl}^{-}$cotransporter (KCC2) interacting protein and required for neuronal $\mathrm{Cl}^{-}$ regulation in hippocampal neurons [15]. Although NETO2 was initially believed to be a brain-specific protein $[9,11]$, a recent study conducted by Oparina et al. revealed that NETO2 mRNA expression was also detectable in a variety of normal non-neural tissues and upregulated in several types of cancers including renal, lung, colon and cervical carcinomas [16]. Moreover, they provided evidence that the NETO2 mRNA level could be a potential marker for early diagnosis in renal cancer and non-small cell lung cancer. These new findings encourage further investigation of its potential clinical significance in human malignancies.

Since the expression pattern and clinical relevance of NETO2 has not been investigated in human CRC, in the present study, we determined both the mRNA and protein expression levels of NETO2 in CRC clinical samples and further analyzed the correlation of NETO2 expression with clinicopathologic features and with patient survival based on tumor stage. Our results demonstrated that increased expression of NETO2 was correlated with tumor progression and might serve as an independent unfavorable prognostic indicator for patients with CRC.

\section{Methods}

\section{Patients and specimens}

Formalin-fixed paraffin-embedded tissue specimens from 292 stages I-III CRC patients who received curative surgery in our hospital (150th Hospital of the People's Liberation Army (PLA), Luoyang, China) from July 2006 to December 2009 were retrieved for immunohistochemistry. The study cohort consisted of CRC patients with typical adenocarcinoma histology as confirmed by pathological analysis. Distribution of the continuous variables of the study cohort was listed in Table 1 . Detailed clinicopathologic characteristics of the patients were listed in Table 2. The follow-up period was defined as the interval from the date of surgery to the date of death or last follow-up. The latest follow-up was updated in September 2014, and the median follow-up time of the study cohort was 66 months (range, 1-98 months). Patients alive at the end of follow-up were censored. Disease-specific survival (DSS) was defined as the interval from the date of surgery to the date that patient died from CRC-related causes. Patients were excluded from the study cohort with the following exclusion criteria: previously received any anticancer therapy; impaired heart, lung, liver, or kidney function; previous malignant disease; died from diseases other than CRC or from unexpected events. TNM staging was classified according to the American Joint Committee on Cancer staging manual (seventh edition). 5 fluoruracilbased adjuvant chemotherapy was given to all stage III patients and a subgroup of stage II patients who had at least one of the following risk factors: pT4, bowel obstruction or perforation, poorly differentiated tumors, or less than 12 lymph nodes discovered after surgery.

A set of 57 paired fresh-frozen CRC samples obtained from stages I-III primary CRC patients who received curative surgery in our hospital from April 2013 to June 2013 were used for quantitative polymerase chain reaction (qPCR) analysis. An independent set of 24 paired fresh-frozen CRC samples obtained from stages I-III CRC patients who received curative surgery in our hospital from July 2013 to August 2013 were used for Western blot analysis. Written informed consent was obtained from each patient and this study was approved by the institutional Ethics Committee of our hospital.

\section{Real-time qPCR analysis}

Real-time qPCR analysis was performed as described previously [17]. Briefly, total RNAs were isolated from frozen specimens using TRIzol Reagent (Ambion, 80706, USA). Reverse transcription was performed using RevertAidTM First Strand cDNA Synthesis Kit (Thermo Scientific, K1622, Lithuania) according to the manufacturer's instructions. qPCR was performed on ABI Prism 7500 Sequence Detection System with SYBR Premix Ex Taq ${ }^{\text {tix }}$ II

Table 1 Distribution of continuous variables of the study cohort $(n=292)$

\begin{tabular}{|c|c|c|c|c|c|}
\hline \multirow[t]{2}{*}{ Variable } & \multirow[t]{2}{*}{ Median } & \multirow{2}{*}{$\begin{array}{l}\text { Mean } \pm \\
\text { SEM }\end{array}$} & \multirow[t]{2}{*}{ Range } & \multicolumn{2}{|c|}{ Percentile } \\
\hline & & & & $25^{\text {th }}$ & $75^{\text {th }}$ \\
\hline Age (years) & 66.0 & $65.5 \pm 0.7$ & $30.0-96.0$ & 58.0 & 74.0 \\
\hline Tumor size $(\mathrm{cm})$ & 5.0 & $5.4 \pm 0.2$ & $1.5-15.0$ & 4.0 & 6.0 \\
\hline Follow-up time (months) & 66.0 & $56.3 \pm 1.6$ & $1.0-98.0$ & 31.0 & 77.0 \\
\hline DSS time (months) & 26.0 & $28.6 \pm 1.7$ & $1.0-80.0$ & 13.0 & 42.0 \\
\hline
\end{tabular}

Abbreviations: SEM, Standard error of the mean; DSS, Disease-specific survival 
Table 2 Association between NETO2 expression and clinicopathologic characteristics of CRC patients in the study cohort

\begin{tabular}{|c|c|c|c|c|}
\hline \multirow[t]{3}{*}{ Characteristics } & \multirow{3}{*}{$\begin{array}{l}\text { No. of } \\
\text { patients (\%) } \\
(n=292)\end{array}$} & \multicolumn{2}{|c|}{ NETO2 expression } & \multirow{3}{*}{$P$ value ${ }^{a}$} \\
\hline & & Low (\%) & High (\%) & \\
\hline & & $(n=115)$ & $(n=177)$ & \\
\hline \multicolumn{4}{|l|}{ Age (years) } & 0.864 \\
\hline$<60$ & $88(30.1)$ & 34 (29.6) & $54(30.5)$ & \\
\hline$\geq 60$ & $204(69.9)$ & 81 (70.4) & $123(69.5)$ & \\
\hline \multicolumn{4}{|l|}{ Sex } & 0.860 \\
\hline Female & $111(38.0)$ & $43(37.4)$ & $68(38.4)$ & \\
\hline Male & $181(62.0)$ & $72(62.6)$ & 109 (61.6) & \\
\hline \multicolumn{4}{|l|}{ Tumor location } & 0.227 \\
\hline Right colon & $88(30.1)$ & $31(27.0)$ & $37(20.9)$ & \\
\hline Left colon & $71(24.4)$ & $34(29.5)$ & $57(32.2)$ & \\
\hline Rectum & $133(45.5)$ & $50(43.5)$ & $83(46.9)$ & \\
\hline \multicolumn{4}{|c|}{ Differentiation grade } & 0.013 \\
\hline Well & $20(6.8)$ & $12(10.4)$ & $8(4.5)$ & \\
\hline Moderate & $222(76.0)$ & $91(79.2)$ & $131(74.0)$ & \\
\hline Poor & $50(17.2)$ & $12(10.4)$ & $38(21.5)$ & \\
\hline \multicolumn{4}{|l|}{ Tumor size $(\mathrm{cm})$} & 0.446 \\
\hline$<5$ & $114(39.0)$ & $48(41.7)$ & $66(37.3)$ & \\
\hline$\geq 5$ & $178(61.0)$ & $67(58.3)$ & $111(62.7)$ & \\
\hline \multicolumn{4}{|l|}{ Local invasion } & 0.049 \\
\hline$T_{1}-T_{2}$ & $48(16.4)$ & $25(21.7)$ & $23(13.0)$ & \\
\hline$T_{3}-T_{4}$ & $244(83.6)$ & $90(78.3)$ & $154(87.0)$ & \\
\hline \multicolumn{4}{|c|}{ Lymph node metastasis } & 0.009 \\
\hline $\mathrm{N}_{0}$ & $164(56.2)$ & $74(64.3)$ & $90(50.8)$ & \\
\hline$N_{1}$ & $101(34.6)$ & $37(32.2)$ & $64(36.2)$ & \\
\hline $\mathrm{N}_{2}$ & $27(9.2)$ & $4(3.5)$ & $23(13.0)$ & \\
\hline \multicolumn{4}{|l|}{ TNM stage } & 0.041 \\
\hline I & $40(13.7)$ & $21(18.3)$ & $19(10.7)$ & \\
\hline$\|$ & $124(42.5)$ & $53(46.1)$ & $71(40.1)$ & \\
\hline III & $128(43.8)$ & $41(35.6)$ & $87(49.2)$ & \\
\hline \multicolumn{4}{|c|}{ No. of examined lymph nodes } & 0.655 \\
\hline$<12$ & $152(52.1)$ & $58(50.4)$ & $94(53.1)$ & \\
\hline$\geq 12$ & $140(47.9)$ & $57(49.6)$ & $83(46.9)$ & \\
\hline \multicolumn{4}{|c|}{ Bowel obstruction/perforation } & 0.537 \\
\hline No & $282(96.6)$ & $112(97.4)$ & $170(96.0)$ & \\
\hline Yes & $10(3.4)$ & $3(2.6)$ & $7(4.0)$ & \\
\hline \multicolumn{4}{|c|}{ Adjuvant chemotherapy } & 0.060 \\
\hline No & 98 (33.6) & $46(40.0)$ & $52(29.4)$ & \\
\hline Yes & $194(66.4)$ & $69(60.0)$ & $125(70.6)$ & \\
\hline \multicolumn{4}{|l|}{ Death } & 0.001 \\
\hline No & $168(57.5)$ & $80(69.6)$ & $88(49.7)$ & \\
\hline Yes & $124(42.5)$ & 35 (30.4) & $89(50.3)$ & \\
\hline
\end{tabular}

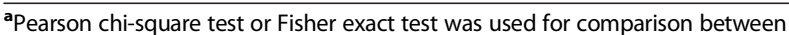
subgroups. Bold type indicates statistical significance
(Takara, RR820A, Japan) using the $2^{-\Delta \Delta C T}$ method. Gene expression results were normalized by internal control $\beta$ actin. The primers used in this study are as follows: NETO2 (NM_001201477.1) forward, 5'-AGCTGCTCCA CGTCAAAGAA-3'; reverse, 5'- GCTCCCGAGAGCTC GAA-3'; $\beta$-actin forward, 5'-AATCGTGCGTGACATTAA GGAG-3'; reverse, 5'-ACTGTGTTGGCGTACAGGTCT T-3'. Each sample was tested in triplicate.

\section{Western blot analysis}

Western blotting was performed as described previously [18]. Briefly, tumor specimens were prepared in lysis buffer [Tris- $\mathrm{HCl}(20 \mathrm{mM}), \mathrm{pH} 7.4, \mathrm{NaCl}(150 \mathrm{mM})$, glycerol (10 \%), Nonidet P-40 (0.2 \%), EDTA (1 mM), EGTA $(1 \mathrm{mM})$, PMSF $(1 \mathrm{mM}), \mathrm{NaF}(10 \mathrm{mM})$, aprotinin (5 $\mathrm{mg} / \mathrm{ml})$, leupeptin $(20 \mathrm{mM})$, and sodium orthovanadate $(1 \mathrm{mM})]$ and centrifuged at $12,000 \mathrm{~g}$ for $30 \mathrm{~min}$. Protein concentrations were measured using the BCA assay. Immunoblotting was performed using a primary antibody specific for NETO2 (Abcam, ab109288) and immunocomplexes were incubated with goat anti-rabbit fluorescein-conjugated secondary antibodies, and then detected using an Odyssey fluorescence scanner (Li-Cor, Gene Company). $\beta$-actin was used as a loading control (Santa Cruz Biotechnology, sc-47778).

\section{Immunohistochemistry and immunocytochemistry}

Immunohistochemistry of paraffin-embedded tissue sections was performed as described previously [19]. Briefly, sections were deparaffinized and rehydrated. The endogenous peroxidase activity was blocked with $3 \%$ $\mathrm{H}_{2} \mathrm{O}_{2}$ for $10 \mathrm{~min}$. Antigens were retrieved with citrate buffer $\left(10 \mathrm{mM}, \mathrm{pH}\right.$ 6.0) for $15 \mathrm{~min}$ at $100{ }^{\circ} \mathrm{C}$ in a microwave oven. After blocking, the sections were incubated with a primary anti-NETO2 antibody (Abcam, ab171651) with 1:200 dilution at $4{ }^{\circ} \mathrm{C}$ overnight in a moist chamber followed by incubated with an anti-rabbit peroxidaseconjugated secondary antibody (Santa Cruz) at room temperature for $30 \mathrm{~min}$. Finally, the visualization signal was developed with diaminobenzidine (Dako) and the slides were counterstained with hematoxylin. Immunocytochemistry was performed using human CRC cell line HCT15 as a positive control for immunostaining of NETO2 and HCT116 as a negative control.

Stained sections were evaluated in a blinded manner without prior knowledge of the clinical data using the German immunoreactive score (IRS) as described previously [20]. Briefly, staining intensity was graded as "0" (negative), "1" (weak), "2" (moderate) and " 3 " (strong); staining extent was graded as " 0 " ( $<5 \%)$, " 1 " (5-25\%), "2" (25-50\%), "3" (50-75\%) or "4" (>75\%). Values of the staining intensity and the staining extent were multiplied as a final IRS of NETO2 expression. Using this method of assessment, we evaluated NETO2 expression 
in CRC tissues by the IRS of $0,1,2,3,4,6,8,9$, or 12 . The median value of the IRS was chosen as the cut-off for high and low NETO2 expression levels based on a measure of heterogeneity according to the log-rank test with respect to DSS, as described previously [21]. An IRS of $\geq 6$ was used to indicate tumors with high NETO2 expression and an IRS of $<6$ was used to define tumors with low NETO2 expression. Discrepancies in the IRS were resolved by discussing together with other pathologists to reach a consensus.

\section{Statistical analysis}

Pearson chi-square test or Fisher exact test was used to analyze the relationship between NETO2 expression and clinical features. Kaplan-Meier analysis with log-rank test was used to compare patients' survival between subgroups. The effect of each variable on survival was determined by the Cox multivariate regression analysis. All statistical analyses were carried out using SPSS PASW Statistics 18.0 software (SPSS, Inc., Chicago, IL), and $p$ value $<0.05$ was considered to be statistically significant.

\section{Results}

\section{Overexpression of NETO2 in primary CRC tissues}

The expression levels of NETO2 mRNA in 57 paired CRC and corresponding adjacent normal mucosa specimens were quantified by real-time qPCR method. The results showed that NETO2 mRNA expression was significantly upregulated in the cancerous tissues compared with adjacent normal counterparts, in which $52.6 \%(30 / 57)$ of the cancerous specimens tested showed a significant increase (over 2 -fold) in NETO2 mRNA level (Fig. 1a, $p<0.01$ ). To determine the protein levels of NETO2 in CRC, an independent set of 24 paired CRC and corresponding adjacent normal mucosa specimens were subjected to Western blot assay. As shown in Fig. 1b, the protein levels of NETO2 were also significantly higher in cancerous tissues than in adjacent normal counterparts $(p<0.001)$.

To further evaluate the phenotypic expression of NETO2 protein in CRC clinical samples, immunohistochemical analysis was performed in another independent set of 292 pairs of CRC specimens and adjacent normal tissues. The immunoreactivity of NETO2 protein was observed primarily in the cytoplasm. The staining intensities were classified into four levels: level 1 with negative staining, level 2 with weak staining, level 3 with moderate staining, and level 4 with strong staining (Fig. 2a). Overall, $9.2 \%(27 / 292)$ of the cancerous specimens showed strong staining, $67.5 \%(197 / 292)$ of the cases showed moderate staining, $18.2 \%(53 / 292)$ of the cases showed weak staining, and only $5.1 \%(15 / 292)$ of the cases showed negative staining of NETO2 protein. In striking contrast, $34.9 \%$ $(102 / 292)$ of the adjacent normal mucosa tissues showed negative staining, $40.8 \%(119 / 292)$ of the cases showed weak staining, $22.9 \%(67 / 292)$ of cases showed moderate staining, and only $1.4 \%(4 / 292)$ of cases showed strong staining of NETO2 (Fig. $2 \mathrm{~b}, p<0.001$ ). Thus, NETO2 was frequently overexpressed in primary CRC tissues.

\section{Correlation of NETO2 expression with clinicopathologic features}

To evaluate the association between NETO2 expression levels and clinicopathologic characteristics, the 292 patients were classified into high and low NETO2 expression subgroups with the median IRS value as the cut-off. As shown in Table 2, high expression of NETO2 protein was significantly correlated with poor tumor differentiation $(p=0.013)$, advanced local invasion $(p=0.049)$, increased lymph node metastasis $(p=0.009)$, advanced TNM stage of the disease $(p=0.041)$, and increased death rate of patients $(p=0.001)$. While, there were no significant associations between NEOT2 expression and patient age $(p=0.864)$, sex $(p=0.860)$, tumor location $(p=0.227)$, tumor size $(p=0.446)$, number of examined lymph nodes $(p=0.655)$, preoperative bowel obstruction or perforation $(p=0.537)$, or adjuvant chemotherapy $(p=0.060)$.

Prognostic values of NETO2 expression for patients with CRC Of the 292 patients, 124 had died from disease progression within the follow-up period. The cumulative 5-year disease-specific survival (DSS) rate was $60.3 \%$. KaplanMeier analysis of the complete study cohort revealed that patients with high-NETO2 tumors had a significantly shorter DSS than those with low-NETO2 tumors (Fig. 3a, $p<0.001)$. The cumulative 5-year DSS rate was $71.3 \%$ in patients with low-NETO2 tumors, whereas it was only $53.1 \%$ in those with high-NETO2 tumors. In our cohort, patients who had advanced stage (stage III) tumors had a significantly unfavorable prognosis compared with those who had early stage (stages I-II) tumors (Fig. 3b, $p<0.001$ ).

Survival analyses based on tumor stage (early and advanced) demonstrated that high expression of NETO2 significantly predicted poor DSS in patients with early stage tumors (Fig. 3c, $p=0.027$ ). Similarly, high levels of NETO2 also significantly predicted poor DSS in patients with advanced stage tumors (Fig. 3d, $p=0.020$ ).

To assess whether NETO2 expression represents an independent prognostic indicator in $\mathrm{CRC}$, the effect of each variable on survival was determined by the Cox regression analysis. Univariate analyses revealed that NETO2 expression $(\mathrm{HR}=1.986,95 \% \mathrm{CI}=1.343-2.937$, $p=0.001)$, TNM stage $(\mathrm{HR}=1.832,95 \% \mathrm{CI}=1.286-2.609$, $p=0.001)$, tumor differentiation grade $(\mathrm{HR}=1.691,95 \%$ $\mathrm{CI}=1.103-2.591, p=0.016)$, and patient age $(\mathrm{HR}=1.674$, $95 \% \mathrm{CI}=1.098-2.551, p=0.017$ ) were significantly associated with DSS (Table 3). The variables that significantly 


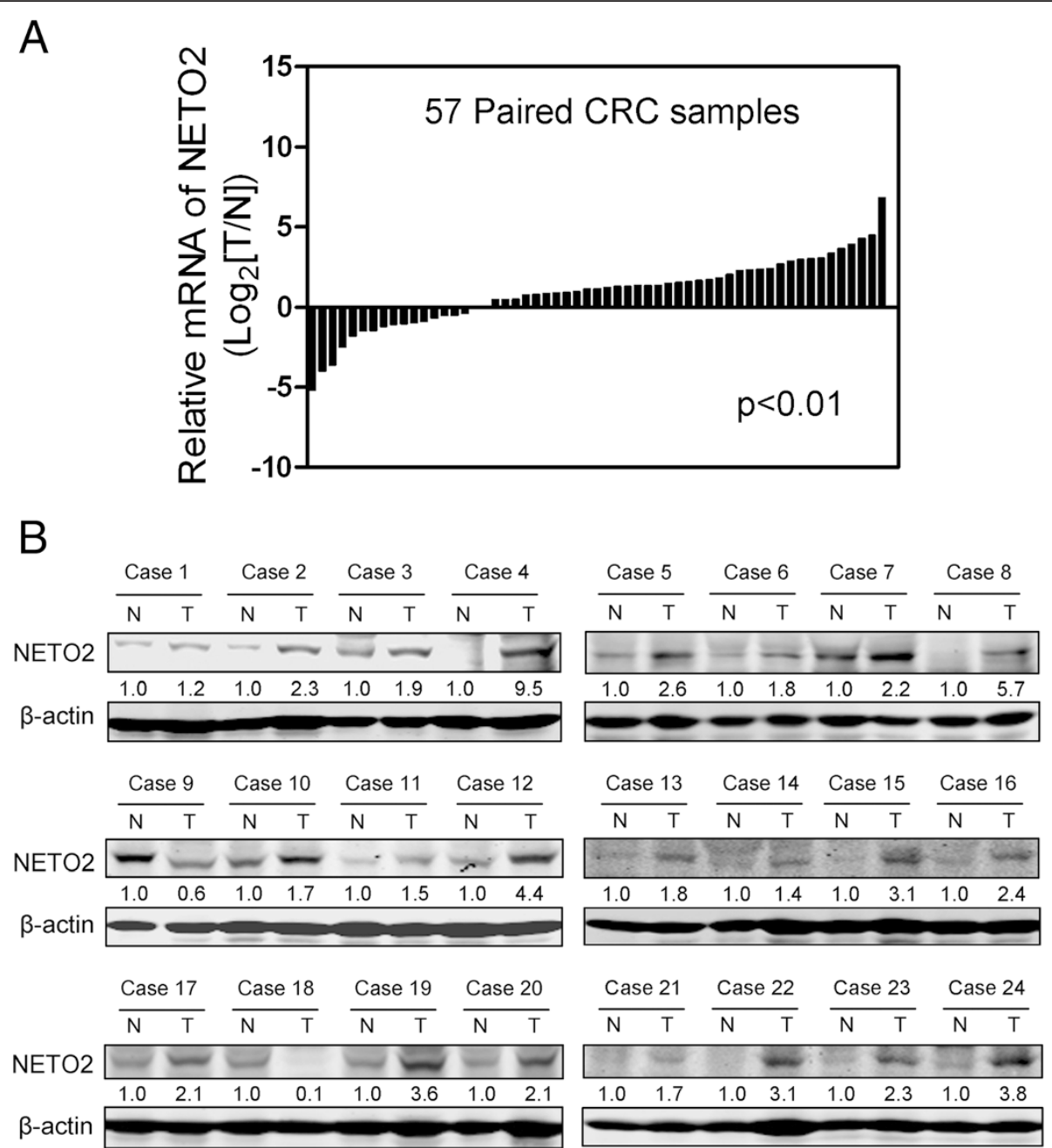

Fig. 1 Expression of NETO2 in primary CRC tissues. a NETO2 mRNA expression in 57 paired human CRC and corresponding adjacent normal mucosa specimens were determined by real-time qPCR method. Gene expression results were normalized by internal control $\beta$-actin. (T, tumor tissues; $N$, adjacent normal tissues). b Protein expression levels of NETO2 in an independent set of 24 paired CRC and corresponding adjacent normal specimens were determined by Western blot analysis. $\beta$-actin was used as a loading control. The relative protein expression of NETO2 was quantified and normalized to $\beta$-actin. Each $N$ was arbitrarily designated 1.0. (T: Tumor tissues; N: adjacent normal tissues, T vs N, $p<0.001$ )

correlated with survival in the univariate analysis were further assessed by multivariate analysis. The results of the multivariate analysis confirmed that NETO2 expression $(\mathrm{HR}=1.924,95 \% \mathrm{CI}=1.300-2.848, p=0.001)$, TNM stage $(\mathrm{HR}=1.878,95 \% \mathrm{CI}=1.313-2.685, p=0.001)$, and patient age $(\mathrm{HR}=1.875,95 \% \mathrm{CI}=1.225-2.871, p=0.004)$ were independent prognostic factors for patients with CRC (Table 3).

The independent prognostic significance of NETO2 expression on CRC-specific survival based on tumor stage was further evaluated with a Cox regression model. The results showed that increased NETO2 expression was an independent indicator of a poor prognosis for patients with early stage tumors $(\mathrm{HR}=1.937,95 \% \mathrm{CI}=1.107$ 3.390, $p=0.021$ ) as well as for those with advanced stage tumors $(\mathrm{HR}=2.241,95 \% \mathrm{CI}=1.245-4.035, p=0.007)$. For patients with advanced stage tumors, age $(\mathrm{HR}=2.229$; $95 \% \mathrm{CI}=1.264-3.932, p=0.006)$ and number of examined lymph nodes $(\mathrm{HR}=0.584 ; 95 \% \mathrm{CI}=0.351$ 0.973, $p=0.039)$ were also significantly associated with patient survival (Table 4).

\section{Discussion}

NETO2 was initially reported to be specifically expressed in the nervous system and previous investigations of this gene focused almost entirely on the neurobiological aspects, but subsequent studies revealed that it is dysregulated in several pathological conditions. Using a genome-wide transcriptional profiling analysis, Calicchio et al. reported that NETO2 belongs to the genes overexpressed in proliferating hemangiomas relative to normal placental vessels [22]. In addition, Horak et al. found that 

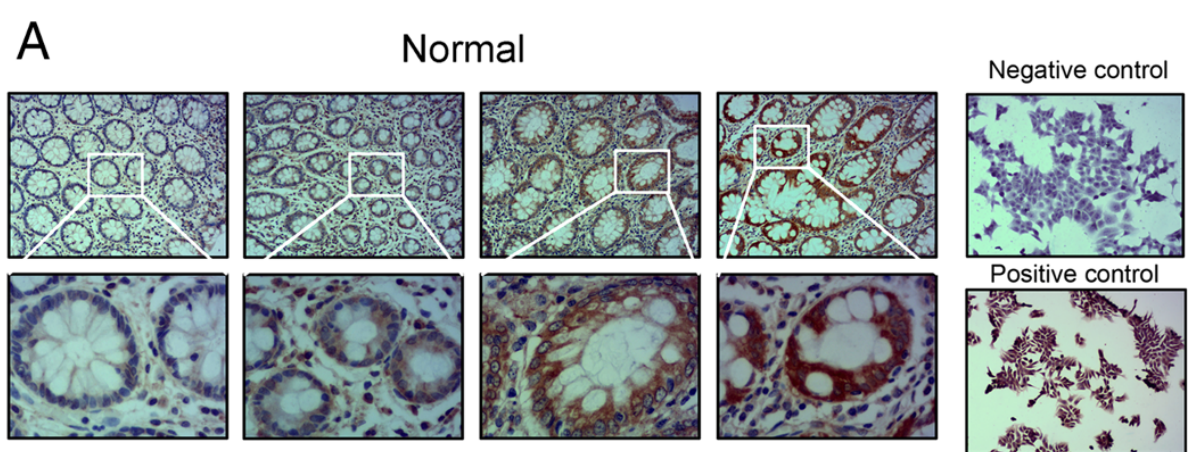

\section{Carcinoma}
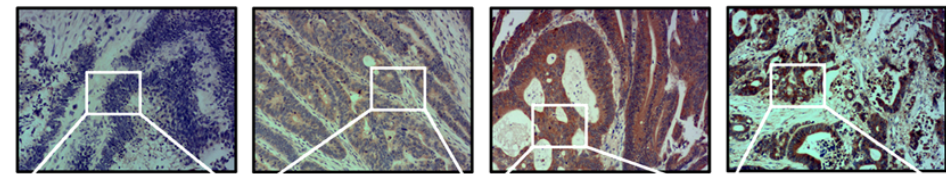

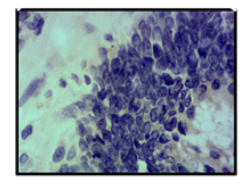

Negative

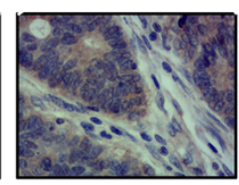

Weak

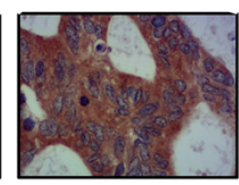

Moderate

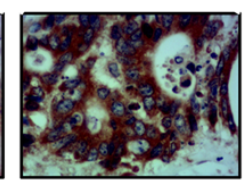

Strong B

NETO2 Staining Intensity

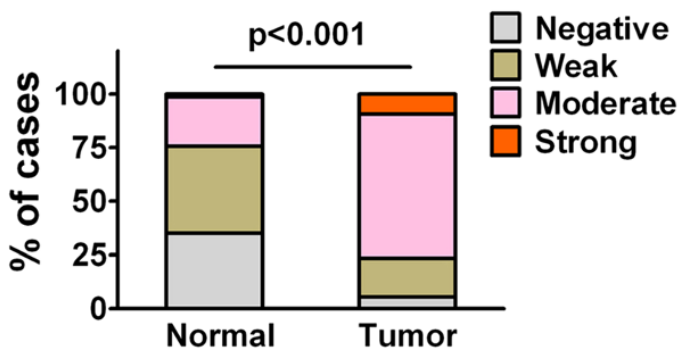

Fig. 2 Immunostaining of NETO2 protein in human CRC and adjacent normal tissues. a Representative immunohistochemical expression patterns of NETO2 in cancerous and adjacent normal mucosa specimens were shown. (Magnification, upper panel, $\times 100 ;$ lower panel, $\times 400$ ) Right panel: human CRC cell line HCT116 cells were used as a negative control and HCT15 cells were used as a positive control for immunostaining of NETO2 protein. (Magnification $\times 100)(\mathbf{b})$ Percentage of cases with different staining intensity of NETO2 in the tumor or adjacent normal tissues in the study cohort. $(p<0.001)$

it could be downregulated by the metastasis suppressor gene Nm23-H1 in breast carcinoma cell lines [23]. Notably, Oparina et al. recently demonstrated that the NETO2 mRNA is frequently overexpressed in a number of human neoplasms and might be a tool to support the early diagnosis of renal and lung carcinomas [16]. These findings indicate that NETO2 may have potential significance in cancer pathobiology. Nevertheless, the clinical relavance of NETO2 expression has not been assessed in CRC.

The present study, to our knowledge, is the first to report the phenotypic expression pattern of NETO2 and its clinical significance in CRC. Using real-time $\mathrm{qPCR}$ and Western blot analysis, we found that NETO2 was frequently overexpressed in primary CRC samples at both the mRNA and protein levels. Our results are consistent with the previous findings of Oparina et al. at the mRNA level [16]. Of note, we observed a significant increase in NETO2 mRNA level (over 2-fold) in $52.6 \%$ $(30 / 57)$ of the cancerous specimens tested, whereas Oparina et al. reported that only $40 \%(4 / 10)$ of colon cancer samples showed substantially increased expression of NETO2 mRNA. This discrepancy may result from the difference in the sample size, ethnic group or endogenous control gene used for normalization. Notably, as these tumor tissues were not isolated by laser capture microdissection technology, the inclusion of non-epithelial cells not expressing NETO2 in 


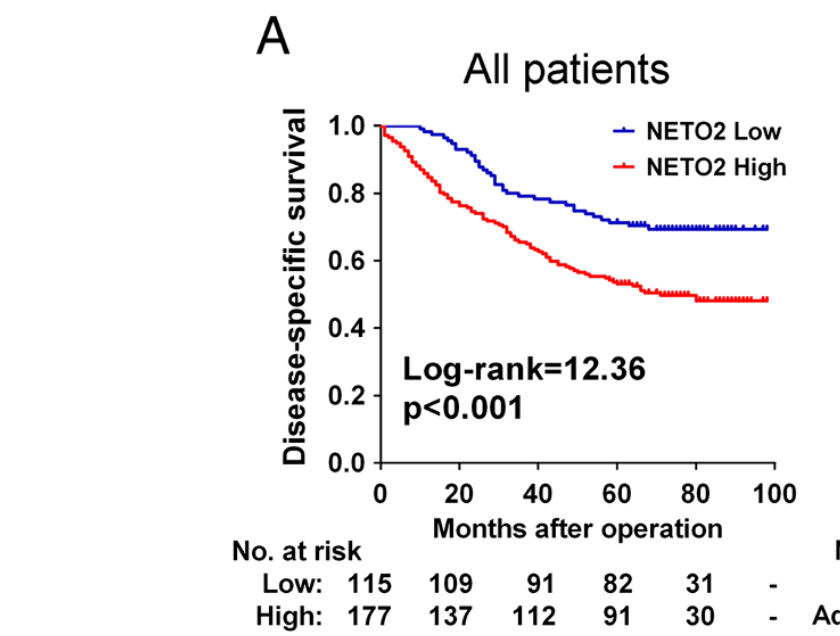

B

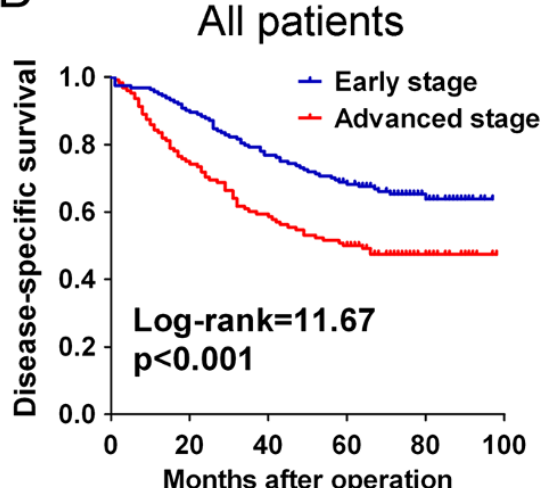

C

Early stage

No. at risk

Months after operation

Early: $\begin{array}{llllll}164 & 148 & 128 & 109 & 43 & -\end{array}$

vanced: $\begin{array}{llllll}128 & 96 & 76 & 63 & 18 & -\end{array}$

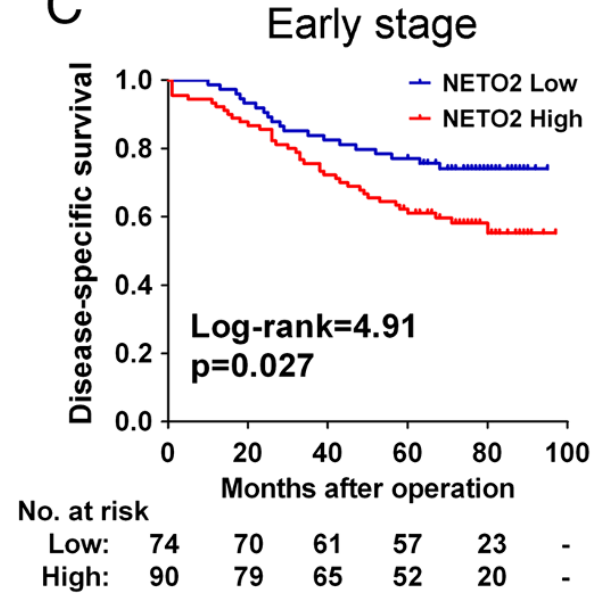

D Advanced stage

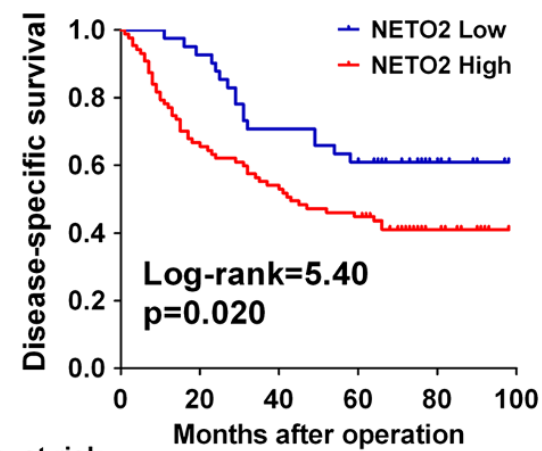

No. at risk

$\begin{array}{lllllrl}\text { Low: } & 41 & 39 & 30 & 25 & 8 & - \\ \text { High: } & 87 & 58 & 47 & 39 & 10 & -\end{array}$

Fig. 3 Kaplan-Meier survival analysis for CRC patients. a Kaplan-Meier curves for disease-specific survival of all CRC patients in the study cohort according to NEOT2 expression status. b Kaplan-Meier curves for disease-specific survival of all CRC patients according to TNM stage. $\mathbf{c}-\mathbf{d}$ Kaplan-Meier curves for disease-specific survival of patients with early stage tumors (c) or advanced stage tumors (d) according to NETO2 expression status. The p-value was determined using the log-rank test. The absolute number of patients at risk in each subgroup is listed below

Table 3 Univariate and multivariate analyses of prognostic factors for disease-specific survival of CRC patients in the study cohort

\begin{tabular}{|c|c|c|c|c|c|c|c|}
\hline \multirow[t]{2}{*}{ Variables } & \multirow[t]{2}{*}{ Categories } & \multicolumn{3}{|c|}{ Univariate analysis } & \multicolumn{3}{|c|}{ Multivariate analysis } \\
\hline & & $\mathrm{HR}$ & $95 \% \mathrm{Cl}$ & $P$ value ${ }^{a}$ & $\mathrm{HR}$ & $95 \% \mathrm{Cl}$ & $P$ value ${ }^{a}$ \\
\hline Age (years) & $\geq 60 /<60$ & 1.674 & $1.098-2.551$ & 0.017 & 1.875 & $1.225-2.871$ & 0.004 \\
\hline Sex & Male/female & 1.141 & $0.791-1.646$ & 0.480 & & & \\
\hline Tumor location & Colon/rectum & 0.960 & $0.674-1.367$ & 0.820 & & & \\
\hline Tumor size (cm) & $\geq 5 /<5$ & 1.161 & $0.807-1.672$ & 0.421 & & & \\
\hline No. of examined lymph nodes & $\geq 12 /<12$ & 0.952 & $0.669-1.354$ & 0.783 & & & \\
\hline Bowel obstruction/perforation & Yes/no & 0.962 & $0.355-2.607$ & 0.940 & & & \\
\hline Adjuvant chemotherapy & Yes/no & 1.246 & $0.851-1.825$ & 0.259 & & & \\
\hline Differentiation grade & Poor well + moderate & 1.691 & $1.103-2.591$ & 0.016 & & & \\
\hline TNM stage & $\|I / I+\|$ & 1.832 & $1.286-2.609$ & 0.001 & 1.878 & $1.313-2.685$ & 0.001 \\
\hline NETO2 expression & High/low & 1.986 & $1.343-2.937$ & 0.001 & 1.924 & $1.300-2.848$ & 0.001 \\
\hline
\end{tabular}

Abbreviations: $\mathrm{HR}$, hazard ratio; $95 \% \mathrm{Cl}, 95 \%$ confidence interval

${ }^{a}$ Bold type indicates statistical significance 
Table 4 Multivariate analyses of prognostic factors for disease-specific survival of patients with early or advanced stage tumors in the study cohort

\begin{tabular}{|c|c|c|c|c|c|c|c|}
\hline \multirow[t]{2}{*}{ Variables } & \multirow[t]{2}{*}{ Categories } & \multicolumn{3}{|c|}{ Early stage } & \multicolumn{3}{|c|}{ Advanced stage } \\
\hline & & $\mathrm{HR}$ & $95 \% \mathrm{Cl}$ & $P$ value $^{b}$ & $\mathrm{HR}$ & $95 \% \mathrm{Cl}$ & $P$ value $^{b}$ \\
\hline Age (years) & $\geq 60 /<60$ & 1.705 & $0.860-3.381$ & 0.127 & 2.229 & $1.264-3.932$ & 0.006 \\
\hline Sex & Male/female & 0.818 & $0.462-1.447$ & 0.489 & 1.575 & $0.934-2.658$ & 0.089 \\
\hline Tumor location & Colon/rectum & 1.095 & $0.802-1.495$ & 0.569 & 0.968 & $0.727-1.290$ & 0.826 \\
\hline Tumor size (cm) & $\geq 5 /<5$ & 0.920 & $0.536-1.579$ & 0.762 & 1.558 & $0.915-2.652$ & 0.103 \\
\hline No. of examined lymph nodes & $\geq 12 /<12$ & 1.525 & $0.785-2.964$ & 0.213 & 0.584 & $0.351-0.973$ & 0.039 \\
\hline Bowel obstruction/perforation & Yes/no & 1.365 & $0.175-10.672$ & 0.767 & 0.689 & $0.209-2.269$ & 0.541 \\
\hline Adjuvant chemotherapy ${ }^{a}$ & Yes/no & 0.808 & $0.397-1.644$ & 0.556 & & & \\
\hline Differentiation grade & Poor/well + moderate & 0.690 & $0.207-2.298$ & 0.545 & 1.591 & $0.946-2.678$ & 0.080 \\
\hline NETO2 expression & High/low & 1.937 & $1.107-3.390$ & 0.021 & 2.241 & $1.245-4.035$ & 0.007 \\
\hline
\end{tabular}

Abbreviations: HR, hazard ratio; $95 \% \mathrm{Cl}, 95 \%$ confidence interval

${ }^{a}$ As all advanced stage patients had received adjuvant chemotherapy, adjuvant chemotherapy was not enrolled into the multivariate analysis

${ }^{b}$ Bold type indicates statistical significance

PCR and Western blot experiments may interfere with the evaluation of NETO2 expression in CRC and adjacent normal tissues. Nevertheless, our subsequent immunohistochemical analysis of 292 paired CRC specimens demonstrated that expression of NETO2 protein was significantly upregulated in the cancerous colorectal epithelial cells compared with the adjacent normal counterparts, in which $76.7 \%(224 / 292)$ of the cancerous tissues presented moderate-strong staining of NETO2 protein, whereas only $24.3 \%$ (71/292) of the adjacent normal tissues showed virtually the same immunoreactivity. Thus, our results unambiguously confirmed the significant upregulation of NETO2 expression in CRC. In addition, unlike the reported transmembrane localization in neurons $[9,11]$, we found that NETO2 protein was mainly localized in the cytoplasm. This observation is in agreement with the results of the Protein Atlas large-scale immunohistochemical study of human proteins, which displayed a cytoplasmic staining of NETO2 in human normal colorectal tissues [http://www.proteinatlas.org/ ENSG00000171208]. Hence, although NETO2 gene was initially found only expressed in brain of human and mice by Northern blotting and in situ hybridization analysis [9], the data collected from Oparina et al. and our group demonstrated that it is also expressed in non-neural normal and neoplastic tissues. Moreover, the observed significant upregulation of NETO2 expression in malignant diseases is in accordance with similar cases where expression of certain neuron-specific proteins is activated in oncogenesis $[24,25]$. However, the molecular basis and biological relevance of NETO2 overexpression in CRC is currently unclear and needs further investigation.

Interestingly, according to our results, increased expression of NETO2 protein in CRC was significantly correlated with poor differentiation, advanced local invasion, increased lymph node metastasis and advanced TNM stage, indicating that NETO2 may be involved in the progression of CRC. It should be noted that, although our data demonstrated an association of NETO2 expression with aggressive clinical phenotypes, whether NETO2 plays a functional role in the progression of CRC needs to be carefully determined. Since the increase in NETO2 expression could also be the result of other factors that lead to cancer progression, rather than NETO2 overexpression being a contributing factor in cancer progression. Further in vitro and in vivo functional studies are warranted to address this issue.

The most important finding of the present study was the prognostic value of NETO2 in CRC patients. We observed a significant association between increased NETO2 protein expression and poor survival of CRC patients in both univariate and multivariate survival analyses. In addition, our results also demonstrated that TNM stage is an important prognostic factor in CRC, which is consistent with the well established adverse prognostic effect of tumor stage [26] and confirms that our cohort was representative and that the survival analyses were valid. Moreover, stage-based survival analyses revealed that increased expression of NETO2 protein in tumors not only significantly predicted poor DSS but also was an independent unfavorable prognostic indicator for patients with early stage tumors as well as for those with advanced stage tumors. These findings should be of particular interest especially for patients who have early stage tumors. It is well known that TNM staging has a great influence on CRC prognosis and is clinically accepted as a solid basis for therapeutic management. However, dilemmas are often raised with respect to the treatment of patients with early stage disease. Generally speaking, patients who had early stage CRCs have a favorable prognosis compared with those who had 
advanced stage CRCs. Nevertheless, a subgroup of patients with early stage disease have an increased risk of early recurrence and death [27]. Hence, it is of particular importance to identify this high-risk subgroup of patients for appropriate treatment. Thus, results from the present work suggest that NETO2 expression status could serve as a promising biomarker to classify patients with early stage tumors into distinct risk subgroups and guide individualized therapeutic strategy.

The present study had several limitations. Although our results revealed the clinicopathologic correlation and prognostic value of NETO2 protein expression in a cohort of CRC patients, the potential role of NETO2 in the development of CRC has not been elucidated. In addition, due to the limitation of follow-up period, the median survival time of patients with low-NETO2 tumors could not be obtained, thus, our current results could not accurately reflect the survival of patients in this subgroup. Besides, since the limited quantity of CRC tissue samples, three independent sets of CRC specimens were used with each set studied with each of the method (qPCR, Western, IHC). Therefore, the fact that different sets were employed makes impossible any direct comparison to specifically answer the question of whether there is a correlation between NETO2 expression in the mRNA and protein levels. Further studies are necessary to confirm our findings and clarify the function and mechanism of NETO2 in the development of CRC.

\section{Conclusions}

We here provide evidence, for the first time, that NETO2 expression was frequently upregulated in CRC tissues at both the mRNA and protein levels. In addition, increased expression of NETO2 was significantly associated with disease progression and poor postoperative outcome of CRC patients. Our results suggest that NETO2 might serve as a novel prognostic molecular marker for patients with CRC and encourage further investigation of its potential role in CRC pathobiology.

\section{Abbreviations}

CRC: colorectal carcinoma; NETO2: neuropilin and tolloid-like 2: DSS: diseasespecific survival; IHC: immunohistochemistry; IRS: immunoreactive score; KARs: kainate receptors; $\mathrm{KCC}$ : $\mathrm{K}^{+}-\mathrm{Cl}^{-}$cotransporter 2; GRIP: glutamate receptor-interacting protein; $\mathrm{Cl}$ : confidence interval; HR: hazard ratio.

\section{Competing interests}

The authors declare that they have no competing interests.

\section{Authors' contributions}

$\mathrm{LH}$ and $\mathrm{HYC}$ performed the immunohistochemistry and interpreted the $\mathrm{IHC}$ results. $L H, G Z Y$, and JC performed the statistical analysis. JC, GZY, DF and YXZ obtained the clinical parameters and survival information. HG and CYQ performed the GPCR analysis. LH, YZ and HF performed the Western blot analysis. LH, QPC and CFG conceived of the study, and participated in its design and coordination. $\mathrm{LH}$ and HYC drafted the manuscript. All authors read and approved the final manuscript.

\section{Acknowledgements}

This work was supported by National Natural Science Foundation of China (81301811).

\section{Author details}

${ }^{1}$ Anal-Colorectal Surgery Institute, 150th Hospital of PLA, Luoyang, China. ${ }^{2}$ Department of Oncology, 150th Hospital of PLA, Luoyang, China. ${ }^{3}$ Department of Colorectal Surgery, 150th Hospital of PLA, Luoyang, China. ${ }^{4}$ Department of Clinical Laboratory, 150th Hospital of PLA, Luoyang, China. ${ }^{5}$ Department of Oncology, Changhai Hospital, Second Military Medical University, Shanghai, China. ${ }^{6}$ Department of Gastrointestine Surgery,

Changzheng Hospital, Second Military Medical University, Shanghai, China.

Received: 12 February 2015 Accepted: 15 December 2015

Published online: 23 December 2015

\section{References}

1. Torre LA, Bray F, Siegel RL, Ferlay J, Lortet-Tieulent J, Jemal A: Global cancer statistics, 2012. CA Cancer J Clin. 2015;65(2):87-108

2. Jemal A, Bray F, Center MM, Ferlay J, Ward E, Forman D. Global cancer statistics. CA Cancer J Clin. 2011;61(2):69-90.

3. Guo P, Huang ZL, Yu P, Li K. Trends in cancer mortality in China: an update. Ann Oncol. 2012;23(10):2755-62.

4. Zheng ZX, Zheng RS, Zhang SW, Chen WQ. Colorectal cancer incidence and mortality in China, 2010. Asian Pac J Cancer Prev. 2014;15(19):8455-60.

5. Sankaranarayanan R, Swaminathan R, Brenner H, Chen K, Chia KS, Chen JG, et al. Cancer survival in Africa, Asia, and Central America: a populationbased study. Lancet Oncol. 2010;11(2):165-73.

6. Brenner H, Bouvier AM, Foschi R, Hackl M, Larsen IK, Lemmens V, et al. Progress in colorectal cancer survival in Europe from the late 1980s to the early 21st century: the EUROCARE study. Int J Cancer. 2012;131(7):1649-58.

7. Brenner H, Kloor M, Pox CP. Colorectal cancer. Lancet. 2014;383(9927):1490-502.

8. Nagtegaal ID, Quirke P, Schmoll HJ. Has the new TNM classification for colorectal cancer improved care? Nat Rev Clin Oncol. 2012;9(2):119-23.

9. Stohr $\mathrm{H}$, Berger $\mathrm{C}$, Frohlich $\mathrm{S}$, Weber $\mathrm{BH}$. A novel gene encoding a putative transmembrane protein with two extracellular CUB domains and a lowdensity lipoprotein class A module: isolation of alternatively spliced isoforms in retina and brain. Gene. 2002;286(2):223-31.

10. Dingledine R, Borges K, Bowie D, Traynelis SF. The glutamate receptor ion channels. Pharmacol Rev. 1999;51(1):7-61.

11. Zhang W, St-Gelais F, Grabner CP, Trinidad JC, Sumioka A, Morimoto-Tomita M, et al. A transmembrane accessory subunit that modulates kainate-type glutamate receptors. Neuron. 2009;61(3):385-96.

12. Straub C, Zhang W, Howe JR. Neto2 modulation of kainate receptors with different subunit compositions. J Neurosci. 2011;31(22):8078-82.

13. Tomita S, Castillo PE. Neto1 and Neto2: auxiliary subunits that determine key properties of native kainate receptors. J Physiol. 2012;590(Pt 10):2217-23.

14. Tang M, Ivakine E, Mahadevan V, Salter MW, McInnes RR. Neto2 interacts with the scaffolding protein GRIP and regulates synaptic abundance of kainate receptors. PLoS One. 2012;7(12), e51433.

15. Ivakine EA, Acton BA, Mahadevan V, Ormond J, Tang M, Pressey JC, et al. Neto2 is a KCC2 interacting protein required for neuronal $\mathrm{Cl}$ - regulation in hippocampal neurons. Proc Natl Acad Sci U S A. 2013;110(9):3561-6.

16. Oparina N, Sadritdinova AF, Snezhkina AV, Dmitriev AA, Krasnov GS, Senchenko VN, et al. Increase in NETO2 gene expression is a potential molecular genetic marker in renal and lung cancers. Genetika. 2012;48(5):599-607.

17. Hu L, Chen L, Yang G, Li L, Sun H, Chang Y, et al. HBx sensitizes cells to oxidative stress-induced apoptosis by accelerating the loss of $\mathrm{Mcl}-1$ protein via caspase-3 cascade. Mol Cancer. 2011;10:43.

18. Hu L, Chen L, Li L, Sun H, Yang G, Chang Y, et al. Hepatitis B virus X protein enhances cisplatin-induced hepatotoxicity via a mechanism involving degradation of Mcl-1. J Virol. 2011;85(7):3214-28.

19. Wang RY, Chen L, Chen HY, Hu L, Li L, Sun HY, et al. MUC15 inhibits dimerization of EGFR and PI3K-AKT signaling and is associated with aggressive hepatocellular carcinomas in patients. Gastroenterology. 2013:145(6):1436-1448 e1431-1412.

20. Tang L, Tan YX, Jiang BG, Pan YF, Li SX, Yang GZ, et al. The prognostic significance and therapeutic potential of hedgehog signaling in intrahepatic cholangiocellular carcinoma. Clin Cancer Res. 2013;19(8):2014-24. 
21. Li W, Yu CP, Xia JT, Zhang L, Weng GX, Zheng HQ, et al. Sphingosine kinase 1 is associated with gastric cancer progression and poor survival of patients. Clin Cancer Res. 2009;15(4):1393-9.

22. Calicchio ML, Collins T, Kozakewich HP. Identification of signaling systems in proliferating and involuting phase infantile hemangiomas by genome-wide transcriptional profiling. Am J Pathol. 2009;174(5):1638-49.

23. Horak CE, Lee JH, Elkahloun AG, Boissan M, Dumont S, Maga TK, et al. Nm23-H1 suppresses tumor cell motility by down-regulating the lysophosphatidic acid receptor EDG2. Cancer Res. 2007;67(15):7238-46.

24. Coulson JM, Ahmed SI, Quinn JP, Woll PJ. Detection of small cell lung cancer by RT-PCR for neuropeptides, neuropeptide receptors, or a splice variant of the neuron restrictive silencer factor. Methods Mol Med. 2003;75:335-52.

25. Gurrola-Diaz C, Lacroix J, Dihlmann S, Becker CM, von Knebel DM. Reduced expression of the neuron restrictive silencer factor permits transcription of glycine receptor alpha1 subunit in small-cell lung cancer cells. Oncogene. 2003;22(36):5636-45.

26. Webber C, Gospodarowicz M, Sobin LH, Wittekind C, Greene FL, Mason MD, et al. Improving the TNM classification: findings from a 10-year continuous literature review. Int J Cancer. 2014;135(2):371-8.

27. Lugli A, Karamitopoulou E, Zlobec I. Tumour budding: a promising parameter in colorectal cancer. Br J Cancer. 2012;106(11):1713-7.

Submit your next manuscript to BioMed Central and we will help you at every step:

- We accept pre-submission inquiries

- Our selector tool helps you to find the most relevant journal

- We provide round the clock customer support

- Convenient online submission

- Thorough peer review

- Inclusion in PubMed and all major indexing services

- Maximum visibility for your research

Submit your manuscript at www.biomedcentral.com/submit
Biomed Central 